\title{
Biotransformation of Terfenadine to Fexofenadine by Absidia corymbifera ATCC 14058
}

\author{
Tankeswar Nath*, Manab Bikash Gogoi and Pranab Kumar Nath \\ DBT-AAU Centre, Assam Agricultural University, Jorhat-785013, India \\ *Corresponding author
}

K e y w o r d s
Absidia corymbifera
ATCC 14058,
Terfenadine,
Fexofenadine,
Biotransformation,
Molar conversion
Article Info
Accepted:
24 June 2018
Available Online:
10 July 2018

Key words

Absidia corymbifera

ATCC 14058,

Terfenadine,

Biotransformation,

Molar conversion

A B S T R A C T
Fexofenadine is an important medicament having significant antihistaminic activity. It is currently being prepared by chemical route which is in numerous stages of development with a yield of less than $10 \%$. In this study, bio-transformation of terfenadine to fexofenadine was investigated using few microbial strains. Among the microbes studied, Absidia corymbifera ATCC14058 showed the highest conversion efficiency in a base line study. Therefore, process conditions conducive to conversion of terfenadine to fexofenadine were optimized using this strain. The growing cell-masses of this strain showed the maximum molar conversion of $99.19 \%$ and $94.76 \%$ at $200 \mathrm{ppm}$ and 500ppm substrate concentration, respectively. Above 500ppm substrate concentration, molar conversion efficiency found to be decreased considerably with increased concentration of substrate. However, the split-dose addition of substrate showed better conversion than the single dose addition. Again, growing cell-catalysts showed the highest substrate conversion over the resting cell-catalysts and cell-free extract. This strain also showed the ability to convert terfenadie to fexofendine in biphasic solvent systems. Among the different biphasic systems, the Ethanol-water and Dimethyl formamide (DMF)-water systems showed reasonably good results. The microbial bioconversion of terfenadine to fexafenadine with biphasic system is a new approach and carries greater promise for further research.

\section{Introduction}

Forty Fexofenadine, is a second-generation antihistamine drug prescribed in allergic inflammations (Simpson and Jarvis, 2000). The pro-drug terfenadine was superseded by fexofenadine several years ago, because of the cardio-toxicity of terfenadine at high doses (Prat et al., 1999). However, despite structural similarities of these two compounds, the synthetic route used to prepare terfenadine was found to be poorly efficient for fexofenadine synthesis and gave very low yields (<10\%) (Kawai et al., 1994; Patel et al., 1996; Fang et al., 1998). As per reports available, several microorganisms are able to catalyze the multistep oxidation of terfenadine (Meiwes and Worm, 999; Azerad, 1999) and its analogs (Ouarradi et al., 2010). Among them, reportedly, the fungus Absidia corymbifera and the bacterium Streptomyces platensis are the most efficient in fexofenadine 
synthesis (Mazier et al., 2004). Though, fexofenadine production through microbial route has already been reported, the activity per gram of cells is too low for a scale-up process (Burton et al., 2002). Therefore, an efficient alternative microbial strain as well as efficient microbial-method for transformation of terfenadine into fexofenadine is still being a particular interest of pharmaceutical industry.

Considering the above cited problems and prospect, a preliminary trail for microbial conversion of tefenadine to fexofendine was conducted with two ATCC strains, one MTCC strain and six soil isolates from picolinepyrimidine contaminated soils. Among the tested microbial strains, the strain, $A$. corymbifera ATCC 14058 showed comparatively higher yield without byproducts formation.

Therefore, it was hypothesized that using $A$. corymbifera ATCC 14058, an efficient process for microbial conversion of terfenadine to fexofenadine could be achieved.

\section{Materials and Methods}

\section{Chemical}

Terfenadine and Fexofenadine were purchased from Sigma-Aldrich. Other chemicals were purchased from Merck and Hi-Media. All chemicals were of reagent grade.

\section{Microbes used and culture stocks maintenance}

Six microbial strains, viz., PM-4, T-9, TK-a, TK-b, TK-c and TK-d were isolated from soil samples collected from picoline - pyramidine contaminated soils of Jubilant Life Science, Gajraula, UP; two strains, viz., A. corymbifera ATCC 14049 and A. corymbifera ATCC 14058 were procured from ATCC and the strain, S. platensis MTCC-3026 was procured from MTCC, Chandigarh. All culture stocks were maintained and stored at $4{ }^{\circ} \mathrm{C}$.

\section{Growth of active culture}

The cultures were prepared by growing the individual microbial strain in the media containing bacteriological peptone/soya peptone, $5 \mathrm{~g} / \mathrm{L}$; Yeast Extract, $5 \mathrm{~g} / \mathrm{L} ; \mathrm{MgSO}_{4}$ $7 \mathrm{H}_{2} \mathrm{O}, 0.5 \mathrm{~g} / \mathrm{L} ; \mathrm{NaNO}_{3}, 2 \mathrm{~g} / \mathrm{L} ; \mathrm{KCL}, 0.5 \mathrm{~g} / \mathrm{L}$; $\mathrm{K}_{2} \mathrm{HPO}_{4}, 2 \mathrm{~g} / \mathrm{L} ; \mathrm{KH}_{2} \mathrm{PO}_{4}, 1 \mathrm{~g} / \mathrm{L} ; \mathrm{FeSO}_{4} 7 \mathrm{H}_{2} \mathrm{O}$, $0.02 \mathrm{~g} / \mathrm{L}$ and Glucose, $30 \mathrm{~g} / \mathrm{L}$. Initial $\mathrm{pH}$ was kept at $6.5 .50 \mathrm{ml}$ media in $250 \mathrm{ml}$ Erlenmeyer flasks or $100 \mathrm{ml}$ media in $500 \mathrm{ml}$ Erlenmeyer flasks was used for growing culture under shaking condition in an orbital shaker incubator at $250 \mathrm{rpm}$ and $32^{\circ} \mathrm{C}$.

For measurement of cells dry weight (CDW), $100 \mathrm{ml}$ culture broth was centrifuged/ filtered followed by two times washing with distilled water and then the resulted wet-biomass was dried at $100^{\circ} \mathrm{C}$ for $24 \mathrm{hrs}$.

\section{Biotransformation studies}

Screening of the microbes for oxidation of terfenadine to fexofenadine was done by following the method described by Azerad et al., (2003) with slight modification. Microbial conversion of terfenadine to fexofenadine was done with growing cells, resting cells and with cell free extract.

a) Biotransformation with growing cells: Bioconversion reaction was carried out in a $500 \mathrm{ml}$ Erlenmeyer flask having $100 \mathrm{ml}$ growing culture. Terfenadine was dissolved in ethanol or Dimethyl Formamide (DMF) as it is sparingly soluble in water and then charging of ethanol/DMF-dissolved terfenadine was done after sufficient microbial growth was observed in the flask. Bioconversion reaction was allowed to progress in a mechanical shaker incubator running at $250 \mathrm{rpm}$ and $32^{\circ} \mathrm{C}$. 
b) Biotransformation with resting cells: $100 \mathrm{ml}$ microbial culture broth was harvested by filtration. Harvested hyphal mass was washed with distilled water two times. Moisture from the hyphal mass was absorbed with ordinary blotting paper. Wet-hyphal mass was then suspended in $100 \mathrm{ml} 0.1 \mathrm{M}$ sodium phosphate buffer, $\mathrm{pH} 6.5$ in a $500 \mathrm{ml}$ Erlenmeyer flask. Biotransformation reaction was started just after addition of substrate to it. Reaction was carried out in an orbital shaker incubator at 250rpm and $32^{\circ} \mathrm{C}$.

c) Bio-transformation with cells-free extract: $100 \mathrm{ml}$ actively grown culture was harvested by filtration; two times washing were given to the harvested hyphal biomass with distilled water followed by absorption of the moister from the cells-mass with ordinary blotting paper. The hyphal mass thus prepared then grinded by pestle and mortar using $100 \mathrm{ml}$ $0.1 \mathrm{M}$ sodium phosphate buffer, $\mathrm{pH}$ 6.5. The ground-cells mass-buffer mixture was then centrifuged at 5000rpm and $32^{\circ} \mathrm{C}$ temperature. Resulted supernatant was finally used as cellsfree extract. $100 \mathrm{ml}$ cells-free extract was taken for terfenadine-biotransformation reaction in a $500 \mathrm{ml}$ Erlenmeyer flasks, kept in an orbital shaker at $250 \mathrm{rpm}$ and $32^{\circ} \mathrm{C}$.

d) Bio-transformation with higher dose of substrate addition: For addition of $>500 \mathrm{ppm}$ terfenadine, micronization was done to reduce the size of the substrate molecules wherein terfenadine was first dissolved completely in ethanol at concentration of $20-50 \mathrm{mg} / \mathrm{ml}$ and then sufficient distilled water is added to the solution so that terfenadine gets precipitate.

The precipitate was then separated out by vacuum filtration using $0.5 \mu \mathrm{m}$ filter paper. The separated solid was now ready to add in the reaction media. Preparation of catalyst and conduction of reaction were same as described above.

\section{Analysis}

After incubation with substrate for sufficient times, the culture broth as a sample was withdrawn. The liquid and mycelium of the samples were separated through filtration. Terfenadine/ fexofenadine absorbed in mycelium was extracted with DMF and then both filtrate and the DMF-extract were analyzed by HPLC with column: Inertsil ODS-2V, 250mm length x $4.6 \mathrm{~mm}$; ID x 5.0 $\mu \mathrm{m}$ film thickness; flow, $1.4 \mathrm{ml} / \mathrm{min}$; Temp., $25^{\circ} \mathrm{C}$; Buffer, $0.1 \%(\mathrm{v} / \mathrm{v})$ Perchloric acid and Acetonitrile under ratio, 50:50 (isocratic); wave length, $210 \mathrm{~nm}$, Total run time, $15 \mathrm{~min}$ (injection delay, 5min); Retention time for Terfenadine, $7.65 \mathrm{~min}$ and for fexofenadine, $3.17 \mathrm{~min}$.

\section{Purification of the product}

Resulted fexofenadine was purified following the method described by Azerad et al., (2007) with slight modification. After completion of the reaction, the whole reaction mixture was filtered and washed with water. The resulted filtrate was saturated with $\mathrm{NaCl}$ then extracted 3times with ethyl acetate. The organic phase was dried over $\mathrm{MgSO}_{4}$ then evaporated under reduced pressure. The produced whitish solid residue was then purified by chromatography on a silica gel column using the solvent: $\mathrm{CH}_{2} \mathrm{Cl}_{2}-\mathrm{MeOH}-\mathrm{NH}_{4} \mathrm{OH} \quad$ (82.5:15:2.5). Pure product was recovered having M.p.=190$195^{\circ} \mathrm{C}$-similar to standard fexofenadine. Further authenticity was confirmed by LCMass.

\section{Results and Discussion}

In this present investigation, two ATCC strains, one MTCC strain and six isolates from the soils contaminated with the effluent from a picoline-pyramidine based industry were screened for biotransformation of tefenadine to fexofenadine. Among the tested microbial 
strains, A. corymbifera ATCC 14058 showed comparatively higher yield without byproducts formation in a preliminary studies (Table 1). Thus, this ATCC 14058 strain opens up the possibility of exploring itself for converting terfenadine to fexofenadine and encourages for studying the physiochemical conditions in which this bioconversion can be done efficiently. Therefore, in this study different key parameters for bioconversion of terfenadine to fexofenadine have been optimized using A. corymbifera ATCC 14058 as presented and discussed bellow.

\section{Optimization of growth period before addition of substrate:}

Growth period, especially before addition of substrate plays significant role in bioconversion of terfenadine to fexofenadine with growing microbial cultures. Because, the growth period has direct relationship with active cell-biomass production as well as the required enzyme(s) yield which ultimately influence the bioconversion process. Again, along with the growth period, $\mathrm{pH}$ of the culture is also one of the crucial factors for any bioconversion reaction with growing cellcatalysts. Therefore, the growth period, before addition of the substrate had been optimized considering cell-biomass production, $\mathrm{pH}$ of culture-broth and conversion of terfenadine to fexofenadine by the active cells-mass catalysts (Table 2). Growth period, around 52hrs with $\mathrm{pH} 5.56$ and cell biomass, $6.11 \mathrm{mg} / \mathrm{ml}$ (dry weight basis) showed maximum bioconversion (99.19\% molar conversion). Addition of substrate after $52 \mathrm{hrs}$ incubation showed gradual decline in terfenadine conversion though biomass increased steadily which might be due to increase $\mathrm{pH}$ or some other metabolic reasons or the both. So, $52 \mathrm{hrs}$ incubation period before addition of substrate could be considered the best period for production of active biomasses for the bioconversion of terfenadine to fexofendine.
Optimization of reaction period on fexofenadine production

With respect to substrate concentration, enzyme concentration and other reaction conditions, each reaction has a specific reaction time for completion or specific limit of conversion of substrate to product. In this bioconversion system, the reaction period was critically followed up to 9days (Fig. 1) and it was found that for the maximum conversion (99.35\% molar conversion) it needed about 7days; thereafter, conversion efficiency gradually declined which might be attributed to deactivation of some amount of respective enzyme(s) or some other metabolic reasons of the active biomass itself.

\section{Optimization of substrate concentrations}

Different concentrations of terfenadine, ranges from 200ppm to $1000 \mathrm{ppm}$ were studied to evaluate the conversion efficiency of substrate to product. The results obtained (Fig-2a) showed maximum bioconversion with the substrate concentration 200ppm and then it was decreased gradually with the increase concentration of substrate. However, at 500ppm substrate concentration, it showed considerable conversion efficiency $(94.76 \%$ molar conversion).

In an earlier report, the microbial bioconversions of terfenadine to fexofenadine using various microbial strains, the substrate concentration used was between $200-500 \mathrm{ppm}$, and conversion yield obtained was in the range of $82 \%$ to $93 \%$ (Mazier et al., 2007; Michels and Zirbes, 2003). However, the $A$. corymbifera ATCC 14058 showed $99.35 \%$ to $94.76 \%$ molar conversion with the same range of substrate concentration (i.e. 200- 500ppm). This higher substrate conversion efficiency might be due to superiority of the strain, $A$. corymbifera ATCC 14058 or due to the improvement of process conditions or both. Above the 500ppm substrate concentration the 
molar conversion rate was found gradually declined leaving most of the substrate unreacted which might be associated with substrate or product inhibition or combination of the two.

Besides, the single dosage of substrate addition, higher dosage of substrate was also tested with in split-dose addition of it to verify the substrate and/or product inhibition. For this, 1000ppm of terfenadine was added both in single as well as split-dose. For split-dose addition, it was divided into five doses having 200ppm in each. Each small dose was added at $24 \mathrm{hrs}$ interval.

After completion of the substrate addition in 5days, two extra days were allowed for incubation. After 7days, the results (Fig. 2b) showed $52.09 \%$ molar conversion yield. Interestingly, when the same amount of substrate (i.e. 1000ppm) was added in a single dose keeping other conditions same only $24.16 \%$ molar conversion had been achieved. This decreased substrate conversion efficiency with single dose addition of higher concentration of substrate (1000ppm) at a time might be associated with the substrate inhibition at higher substrate concentration.
Bioconversion of terfenadine to fexofenadine in different reaction systems

Performance of a biochemical reaction is varied with the variation of reaction systems conducted with them. Different reaction systems had been tried to see their influences in the bioconversion of terfenadine to fexofenadine taking normal growing culture system as control. Maximum conversion of terfenadine to fexofenadine $(96.86 \%$ molar conversion at 500ppm substrate concentration) was found with growing culture system only (Fig. 3), indicating that biotransformation of terfenadine to fexofenadine is greatly influenced by the metabolic process of the active cells.

\section{Bioconversion of terfenadine to fexofenadine with different biphasic systems}

Solubility of substrate and product is important for any biochemical reaction which directly influences the substrate conversion. Both terfenadine and fexofenadine are sparingly soluble in water but solubility can be increased by mixing with organic solvents like ethanol, dimethyl formamide (DMF), methanol, hexane etc.

Table.1 Conversion of terfenadine to fexofenadie by various micro-organisms

\begin{tabular}{|l|l|}
\hline Strains & \% conversion* \\
\hline PM4 & - \\
\hline T-9 & - \\
\hline TK-a & + \\
\hline TK-b & + \\
\hline TK-c & + \\
\hline TK-d & - \\
\hline Streptomyces platensis MTCC-3026 & + \\
\hline Absidia corymbifera ATCC 14049 & ++ \\
\hline Absidia corymbifera ATCC 14058 & ++++++ \\
\hline
\end{tabular}

(-), No conversion; (+), $0-5 \%$ conversion; (++), up to $10 \%$ conversion; $(++++++)$, more than $30 \%$ conversion

*Conditions: Growing cells-catalyst, 200ppm substrate concentration added in $48 \mathrm{hrs}$ active culture of $100 \mathrm{ml}$ volume in a $250 \mathrm{ml}$ Erlenmeyer flask, $32^{\circ} \mathrm{C}, 250 \mathrm{rpm}$, and substrate conversion was checked after $72 \mathrm{hrs}$ of substrate addition. 
Table.2 Effect of growth period on fexofenadine production

\begin{tabular}{|c|c|c|c|c|c|}
\hline $\begin{array}{c}\text { Growth period } \\
\text { (hr) }\end{array}$ & \multicolumn{2}{|c|}{ pH of the culture broth } & \multicolumn{2}{c|}{$\begin{array}{c}\text { Active biomasses } \\
\text { (Dry wt. basis, mg/ml) }\end{array}$} & $\begin{array}{c}\text { Molar } \\
\text { Conversion } \\
\text { \% }\end{array}$ \\
\cline { 2 - 6 } & $\begin{array}{c}\text { At substrate } \\
\text { addition time }\end{array}$ & $\begin{array}{c}\text { *During } \\
\text { harvesting }\end{array}$ & $\begin{array}{l}\text { At substrate } \\
\text { addition time }\end{array}$ & $\begin{array}{c}\text { *During } \\
\text { harvesting }\end{array}$ & \\
\hline $\mathbf{2 4}$ & 5.67 & 6.94 & 2.19 & 5.31 & 92.50 \\
\hline $\mathbf{4 2}$ & 5.68 & 6.97 & 3.48 & 7.13 & 93.17 \\
\hline $\mathbf{5 2}$ & 5.56 & 6.98 & 6.11 & 7.26 & 99.19 \\
\hline $\mathbf{6 6}$ & 6.42 & 7 & 9.31 & 8.98 & 96.76 \\
\hline $\mathbf{7 2}$ & 6.45 & 7.19 & 10.01 & 10.83 & 94.58 \\
\hline $\mathbf{9 6}$ & 6.67 & 7.25 & 10.33 & 10.47 & 87.90 \\
\hline $\mathbf{1 3 5}$ & 7.38 & 7.39 & 11.14 & 10.84 & 87.77 \\
\hline
\end{tabular}

Substrate concentration: $200 \mathrm{ppm} ; * 7$ days after the substrate addition

Table.3 Bioconversion of terfenadine to fexofenadine with different solvent systems

\begin{tabular}{|l|c|c|c|c|c|c|c|}
\hline \multirow{2}{*}{$\begin{array}{l}\text { Substrate } \\
\text { concentration } \\
\text { (ppm) }\end{array}$} & \multicolumn{6}{|c|}{ Reaction systems Vs. Molar Conversion \% } \\
\cline { 2 - 9 } & Control & Ethanol conc. (\%,v/v) & \multicolumn{2}{c|}{ DMF conc.(\%,v/v) } \\
\hline (no solvent) & 2 & 4 & 6 & 2 & 4 & 6 \\
\hline $\mathbf{5 0 0}$ & 94.76 & 95.57 & 96.38 & 90.5 & 95.70 & 97.22 & 91.45 \\
\hline $\mathbf{7 0 0}$ & 51.02 & 84.76 & 87 & 64.2 & 90.53 & 92.64 & 65.95 \\
\hline
\end{tabular}

Growth period: $52 \mathrm{hrs}$, Reaction period: 7days

Fig.1 Effect of reaction period for conversion of terfenadine to fexofenadine. Initial substrate concentration was kept at 200ppm. Block-bars shown molar conversion of substrate and the graph shown changes of $\mathrm{pH}$ as the reaction proceeded

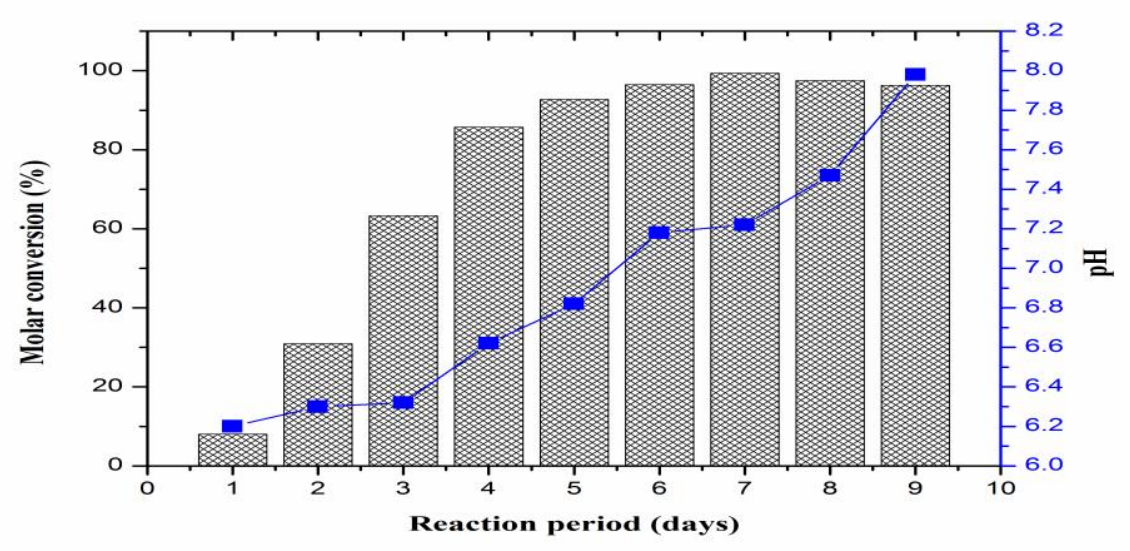


Fig.2A Effect of substrate concentration on production of fexofenadine. Initial growth period: 52hrs, Reaction period: 7days

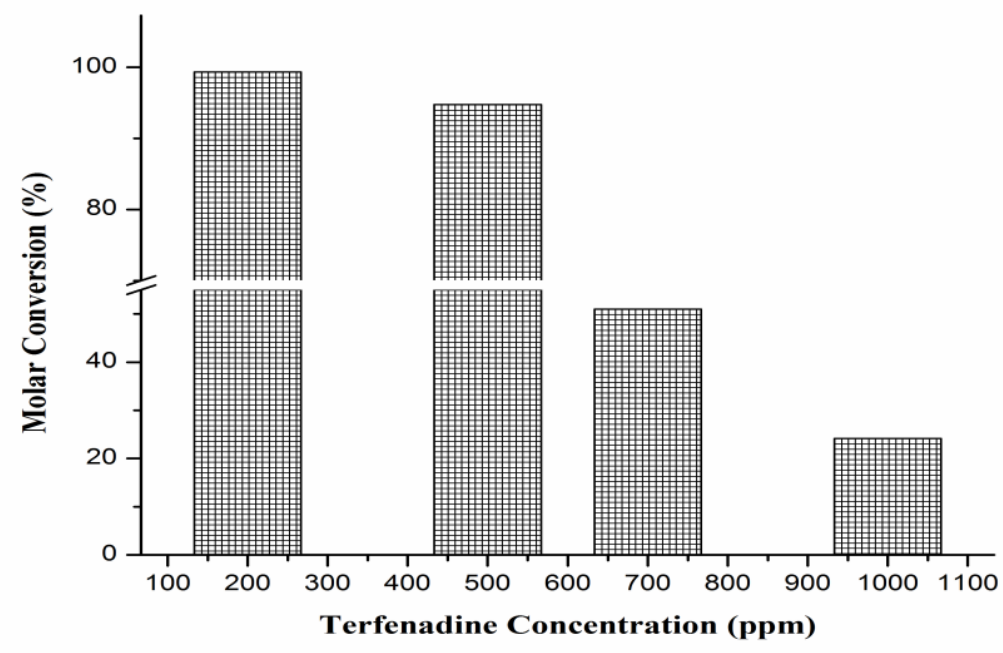

Fig.2B Addition of higher concentration of substrate in split dosage. Initial growth period: 52hrs, Reaction period: 7days

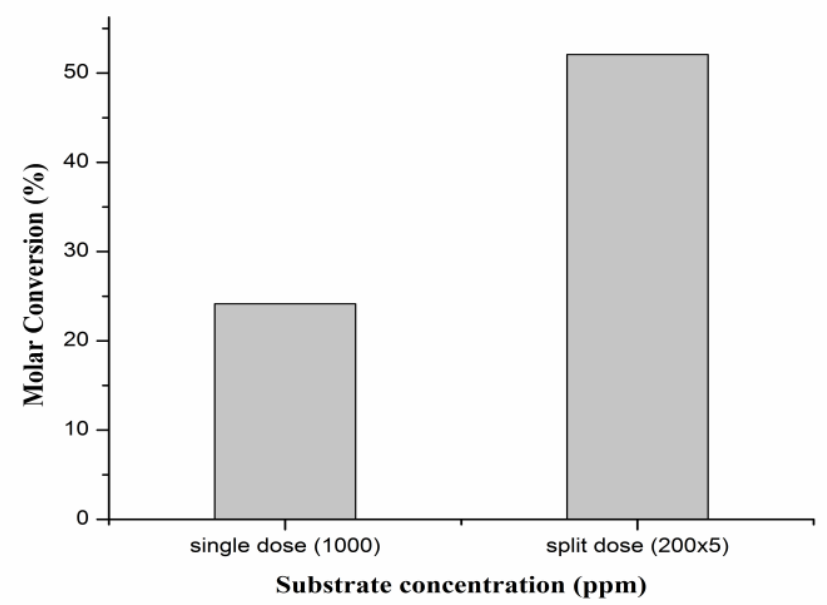

However, addition of the higher concentration of organic solvents found decreased the enzyme activity which might be due to negative effect of organic solvents on enzyme structure and function. Among the different organic solvents screened, ethanol and DMF at lower concentration showed better result in respect of solubility as well as bioconversion yield. Therefore, 2\%, 4\% and 6\% ethanol and DMF were added during the substrate $(500 \mathrm{ppm}$ and 700ppm) addition time, separately. The data obtained (Table 3), showed increased conversion of terfenadine to fexofenadine with the addition of solvents over control (aqueous). Again, between the two solvent systems, DMF was found better over ethanol for all the three concentrations of solvent. Further, $4 \%$ solvent concentration was found to be the best in both the solvent systems. 
In conclusion, the lower conversion of terfenadine to fexofenadine is a major issue in microbial production of fexofenadine. In this study, it was found that the microbial strain, A. corymbifera ATCC 14058 has the capacity to convert terfenadine to fexofendine at higher substrate concentration (up to 500ppm). Above the 500ppm substrate concentrations, conversion yield considerably decreased which might be associated with substrate and/or product inhibition or both. Growing cells catalyst showed more conversion as compared to cell free extract and resting cells catalysts in aqueous reaction system indicting some other active metabolites might be involved for conversion of terfenadine to fexofenadine. Water solubility of the substrate and product is another major issue for biological conversion of terfenadine to fexofenadine. Mixing organic solvent with water at lower concentration, the solubility of the substrate as well as product can be increased and thereby conversion yield can also be increased.

\section{Acknowledgement}

The author are thankful to Jubilant Life Science Ltd. (Previously Jubilant Organosys Ltd.), Gajraula, UP, for providing space to carry out some crucial part of the research.

\section{References}

Azerad, R. 1999. Microbial models for drug metabolism. Adv Biochem Eng Biotechnol. 63: 169-218.

Azerad, R., Biton, J. and Lacroix, I. 2003. Process for the preparation of Fexofenadine, US patent 6558931.

Azerad, R., Biton, J. and Lacroix, I. 2007. Process for the preparation of Fexofenadine. US patent 7241601.

Burton, S. G., Cowan, D. A. and Woodley, J. M. 2002. The search for the ideal biocatalyst. Nat. Biotechnol, 20: 37-45.

Fang, Q. K., Senanayake, C. H., Wilkinson, H. S., Wald. S. A. and Li, H. 1998. An efficient and facile synthesis of racemic and optically-active fexofenadine. Tetrahedron Lett. 39: 2701-2704.

Kawai, S. H., Hambalek, R. J. and Just, G. 1994. A facile synthesis of an oxidation product of terfenadine. J Org Chem, 59: 26202622.

Mazier, C., Jaouen, M., Sari, M. A. and Buisson, D. 2004. Microbila oxidation of terfenadine and ebastine into fexofenadine and carbastine. Bioorganic and Medical Chemistry Letter. 14(21): 5423-5426.

Mazier, C., Lombard, M., Sari, M. A. and Buisson, D. 2007. Oxidation of terfenadine by Streptmyces platensis: Influence of culture media on metabolite formation. Biocatalysis and Biotransformation. 25(5): 401-407.

Meiwes, J., and Worm, M. 1999. Process for the preparation of 4-(4-(4(Hydroxybiphenyl)-1-Piperidinyl)-1-

Hydroxybutyl)- $\alpha, \alpha$-Dimethylphenyl acetic acid and Phosphorelated derivatives. US Patent. 5990127.

Michels, P. C. and Zirbes, E. L. 2003. Process for production of piperidine derivatives with microorganisms, US patent 7691615 B2.

Ouarradi, A. El., Lombard, M. and Buisson, D. 2010. Biooxidation of methyl group: Part 2, Evidences for the involvement of cytochromes $\mathrm{P} 450$ in microbial multistep oxidation of terfenadine. J Mol Catal, B: Enzymatic, 67: 172-178.

Prat, C. M., Mason, J., Russel, T., Reynolds, R. and Ahlbrandt, R. 1999. Cardiovascular safety of fexofenadine HCl. Am J Cardiol. 83: 1451-1454.

Patel, S., Waykole, L. Repic, O. and Chen, K. M. 1996. Synthesis of terfenadine carboxylate. Synth. ommun, 26: 46994710.

Simpson, K. and Jarvis, B. 2000. Fexofenadine: a review of its use in the management of seasonal allergic rhinitis and chronic idiopathic urticaria. Drug. 59: 301-321.

\section{How to cite this article:}

Tankeswar Nath, Manab Bikash Gogoi, Pranab Kumar Nath. 2018. Biotransformation of Terfenadine to Fexofenadine by Absidia corymbifera ATCC 14058 Int.J.Curr.Microbiol.App.Sci. 7(07): 3127-3134. doi: https://doi.org/10.20546/ijcmas.2018.707.365 